\title{
A Defect in the Twin-Arginine Translocation Pathway Decreases the Tolerance of Xanthomonas campestris pv. campestris to Phenazines
}

\author{
Jian Wu, ${ }^{1,2}$ Xiayan Pan, ${ }^{1}$ Shu Xu, ${ }^{1}$ Yabing Duan, ${ }^{1}$ Jueyu Wang, ${ }^{1}$ Jianxin Wang, ${ }^{1}$ Tongchun Gao, ${ }^{2}$ Yong Zhang,,${ }^{2 \dagger}$ and \\ Mingguo Zhou ${ }^{1, \dagger}$
}

${ }^{1}$ College of Plant Protection, State \& Local Joint Engineering Research Center of Green Pesticide Invention and Application, Nanjing Agricultural University, Nanjing, 210095, China

2 Institute of Plant Protection and Agro Product Safety, Anhui Academy of Agricultural Sciences, Hefei, 230001, China

Accepted for publication 11 July 2020.

\begin{abstract}
Phenazine-1-carboxylic acid (PCA), a member of phenazines secreted by microorganisms, inhibits the growth of many bacteria and fungi. Xanthomonas campestris pv. campestris is the causal agent of black rot, the most important disease of cruciferous crops worldwide, and is more tolerant to PCA than other Xanthomonas species. Previous studies reported that reactive oxygen species (ROS) scavenging ability is involved in regulating the PCA tolerance of Xanthomonas species. Additionally, the cytochrome $c$ maturation (CCM) system has been found to play a more important role in tolerance to phenazines than the ROS scavenging system. In this study, a highly PCA-sensitive insertion mutant of $X$. campestris pv. campestris, X-5, was identified and studied. The insertion site of X-5 was found to be in tatB gene (XC_4183), which encodes a subunit of the twin-arginine translocation (TAT) complex. Disruption of the three genes of TAT pathway resulted in decreased
\end{abstract}

ABSTRACT biological fitness and reduced tolerance to phenazines in comparison with the wild-type strain 8004. These results imply that the tolerance mechanism of the TAT pathway to phenazines is related to the CCM system, but not due to the ROS scavenging system. Furthermore, respiration-related characteristic tests and peptide analysis suggested that disruption of the TAT complex causes a defect in the cytochrome bc1 complex, which may be involved in the tolerance to phenazines. In summary, this study sheds new light on the critical role of the TAT pathway in influencing the fitness and phenazines tolerance of Xanthomonas species.

Keywords: genetics and resistance, phenazines, respiration, tolerance, twin-arginine translocation pathway, Xanthomonas campestris pv. campestris
Xanthomonas species cause most bacterial plant diseases, resulting in severe yield and quality loss in many crops worldwide (Hayward 1993). X. campestris pv. campestris, the causal agent of black rot, can infect many important cruciferous crops, including broccoli, cabbage, radish, cauliflower, and oilseed rape (Qian et al. 2005; Roberts et al. 2007). Citrus bacterial canker, which is caused by $X$. citri pv. citri, is a serious disease that significantly impacts citrus production (Jalan et al. 2011). Rice bacterial leaf blight (BLB), caused by X. oryzae pv. oryzae, and rice bacterial leaf streak (BLS), caused by $X$. oryzae pv. oryzicola, have recently been spreading across Asia (Lu et al. 2014; Zhang and Wang 2013). Strategies to control bacterial diseases have had limited success and mainly depend on cultivating resistant varieties, planting bacteriafree seeds and avoiding contamination (Cerutti et al. 2017; Taylor et al. 2002; Vicente and Holub 2013). Bactericides, such as streptomycin, have shown significant effectiveness against bacterial pathogens (Förster et al. 2015). However, the use of antibiotics on agricultural products is being restricted due to the concerns about the development of antibiotic resistance (Sundin and Wang 2018). Therefore, it is necessary to develop novel bactericides for controlling Xanthomonas species.

${ }^{\dagger}$ Corresponding authors: M. Zhou; mgzhou@njau.edu.cn, and Y. Zhang; 135419557@qq.com

Funding: This research was supported by the National Natural Science Foundation of China (31272065), the Natural Science Foundation of Anhui Province (2008085QC125), and the Research Projects of Anhui Academy of Agricultural Sciences (2020YL075).

The author(s) declare no conflict of interest.

(C) 2020 The American Phytopathological Society
Phenazines are a class of antibiotics extracted from microorganisms (Baron and Rowe 1981; Morales et al. 2010), and are wellknown for their potent antimicrobial activities against many organisms, including parasites, nematodes, fungi and bacteria (Laursen and Nielsen 2004; Morales et al. 2010; Xu et al. 2015; Zhou et al. 2016). In previous studies, phenazines were reported to impact a variety of processes in organisms, such as the intracellular reactive oxygen species (ROS) balance, DNA intercalation, respiration and biofilm formation (Gwee Kyo et al. 2011). In addition to their ability to inhibit the growth of specific microorganisms, phenazines have also been shown to accumulate around the rhizosphere, and have a relatively short half-life (3 to 4 days) in soil (Mavrodi et al. 2013). Historically, the low yield and difficult extraction of phenazines limited their use. However, with the development of genetic engineering and fermentation technology in recent years, the use of phenazines has become possible (Du et al. 2015). So far, phenazine-1-carboxylic acid (PCA), the biosynthetic precursor of the other phenazines, has been used for controlling rice sheath blight caused by Rhizoctonia solani, cucumber downy mildew caused by Pseudoperonospora cubensis, Fusarium head blight caused by Fusarium graminearum, and many other plant diseases in China (http://www.icama.org.cn).

In our previous study, PCA exhibited a strong inhibitory effect against $X$. oryzae pv. oryzae and a weak inhibitory effect against $X$. oryzae pv. oryzicola, $X$. campestris pv. campestris, and $X$. citri $\mathrm{pv}$. citri (Xu et al. 2015). In addition, Pan et al. (2017, 2018) reported that defects in the transcriptional regulation factor of the ROS scavenging system, oxyR, and the catalase, CatB, decreased the PCA tolerance in both $X$. oryzae pv. oryzae and $X$. oryzae $\mathrm{pv}$. oryzicola. However, complementation of the $\operatorname{oxy} R$ deletion mutant of $X$. oryzae pv. oryzae with the oxyR fragment of $X$. oryzae pv. oryzicola increased the ROS scavenging ability of $X$. oryzae $\mathrm{pv}$. oryzae but did not affect the PCA tolerance, indicating that some 
other mechanisms are involved in PCA tolerance (Pan et al. 2017, 2018). A study utilizing a transposon insertion mutant library of $X$. campestris pv. campestris demonstrated that cytochrome $c$ proteins play a more important role in regulating tolerance to phenazines than the ROS scavenging system, and that the tolerance mechanism of cytochrome $c$ proteins differs from that of the ROS scavenging system (Pan et al. 2018; Wu et al. 2019).

In this study, one PCA highly sensitive insertion mutant, X-5, was screened from the $X$. campestris pv. campestris insertion mutant library. By employing the plasmid rescue method, a gene of the twin-arginine translocation (TAT) pathway was identified as being disrupted by a transposon in X-5. The TAT pathway, also called the sec-independent preprotein translocation system, is an essential protein transport system that works in parallel with the sec dependent translocation system (Costa et al. 2015; Fröbel et al. 2012; Goosens and van Dijl 2017). The TAT complex generally consists of a hexahelical TatC-type protein and one or two TatA-like proteins (Fröbel et al. 2012). Multiple TatA-like proteins, which are termed TatA, TatB, and TatE, have been found in different species (Berks 2015). However, in some species, TatB and TatE seem to be unnecessary (Lee et al. 2006). In X. campestris pv. campestris, the TAT complex consists of three subunits, named TatA, TatB, and TatC (Qian et al. 2005). The TAT pathway is mainly responsible for exporting folded proteins across the cytoplasmic membrane or helping proteins achieve correct conformation, including proteins that contain molybdopterin cofactors, nucleotide-based cofactors, iron-sulfur clusters, and some other structures. Proteins folded and transported by this pathway are involved in many important cellular activities (Berks 2015; Goosens and van Dij1 2017; Lee et al. 2006; Palmer and Berks 2012). However, there has not been any report focused on how the TAT pathway impacts tolerance to phenazines.

\section{MATERIALS AND METHODS}

Bacterial strains, media, and bactericides. The strains and plasmids used in this study are listed in Table 1 . X. campestris pv. campestris strains were grown at $28^{\circ} \mathrm{C}$ in nutrient broth (NB) media or on nutrient agar (NA) media. The Escherichia coli strain was grown at $37^{\circ} \mathrm{C}$ in Luria-Bertani (LB) broth media or on LB agar media. NB media contained $3 \mathrm{~g}$ of beef extract, $5 \mathrm{~g}$ of polypeptone, $1 \mathrm{~g}$ of yeast extract, and $10 \mathrm{~g}$ of sucrose per liter of distilled water. NA media contained the same components as NB media, with the addition of $16 \mathrm{~g}$ of agar per liter of distilled water. LB agar media contained $5 \mathrm{~g}$ of yeast extract, $10 \mathrm{~g}$ of $\mathrm{NaCl}, 10 \mathrm{~g}$ of tryptone, and $16 \mathrm{~g}$ of agar per liter of distilled water. LB broth media contained the same components as LA media but lacked agar. The NAN, NBN, and NAS media were used in the transformation assays (Yu et al. 2015). NBN media contained the same components as NB media but lacked sucrose. NAN media contained the same components as NBN media, with the addition of $16 \mathrm{~g}$ of agar per liter of distilled water. NAS media contained the same components as NB media, with an additional $100 \mathrm{~g}$ of sucrose per liter of distilled water. XCM media was used for oxidant accumulation assays and contained $10.5 \mathrm{~g}$ of $\mathrm{K}_{2} \mathrm{HPO}_{4}, 4.5 \mathrm{~g}$ of $\mathrm{KH}_{2} \mathrm{PO}_{4}, 1 \mathrm{~g}$ of $\left(\mathrm{NH}_{4}\right)_{2} \mathrm{SO}_{4}, 0.12 \mathrm{~g}$ of $\mathrm{MgSO}_{4}, 2.36 \mathrm{~g}$ of succinic acid, and $1.5 \mathrm{~g}$ of casein acid hydrolysate per liter of distilled water (Xu et al. 2015). The bactericide PCA (98\%) was purchased from Shanghai Nongle Biological Products Co. Ltd. (China). Kanamycin was purchased from Sigma-Aldrich Co. Ltd. (China). Captan was purchased from Guanlong Agrochemical Co. Ltd. (China). Phenazine and 1-OH-phenazine were purchased from Tokyo Chemical Industry Co. Ltd. (Japan). All bactericides were dissolved in acetone, with the exception of kanamycin, which was dissolved in distilled water.

PCA sensitivity. PCA sensitivity, as indicated by $\mathrm{EC}_{50}$ value, was determined in NB media with a turbidity indicator according to a previous study (Xu et al. 2015). The cell cultures were grown to an optical density (OD) 600 of approximately 1.0 (about $10^{9} \mathrm{CFU} / \mathrm{ml}$ ) in a shaker $(175 \mathrm{rpm})$ and diluted to $10^{7} \mathrm{CFU} / \mathrm{ml}$. A $100 \mu \mathrm{l}$ volume of diluted cultures was added to the conical flasks containing $25 \mathrm{ml}$ of NB media amended with different concentrations of PCA. After the cultures were shaken $(175 \mathrm{rpm})$ for $24 \mathrm{~h}$ at $28^{\circ} \mathrm{C}$, the turbidity was measured. The data were analyzed with DPS software (Duan et al. 2013). Each combination of strain and PCA concentration was represented by three replicates, and the experiment was performed four times.

Plasmid rescue. The insertion site of the PCA-sensitive mutant X-5 was identified via the plasmid rescue method (Fig. 1B), which utilized the self-contained ori promoter and a kanamycin resistance-selective gene in the transposon (Grant et al. 1990). Genomic DNA was extracted with a DNA Prep Pure Cell/Bacteria Kit (Tiangen Co. Ltd., Beijing, China) (Yu et al. 2015). The genomic DNA of X-5 was digested with the restriction endonuclease EcoRI, and the enzyme-digested products were then treated with DNA ligase. The ligation products were transformed into E. coli S17$1 \lambda$ pir, and the transformants were then screened on plates containing kanamycin at $20 \mathrm{mg} / \mathrm{liter}$. The plasmids present in the positive colonies were sequenced, and BLAST was employed to search the sequencing results against the National Center for Biotechnology Information database (NCBI) (https://www.ncbi. nlm.nih.gov). The sequencing primers, RP-F and RP-R, are listed in Table 2 .

TABLE 1. Strains and plasmids used in this study

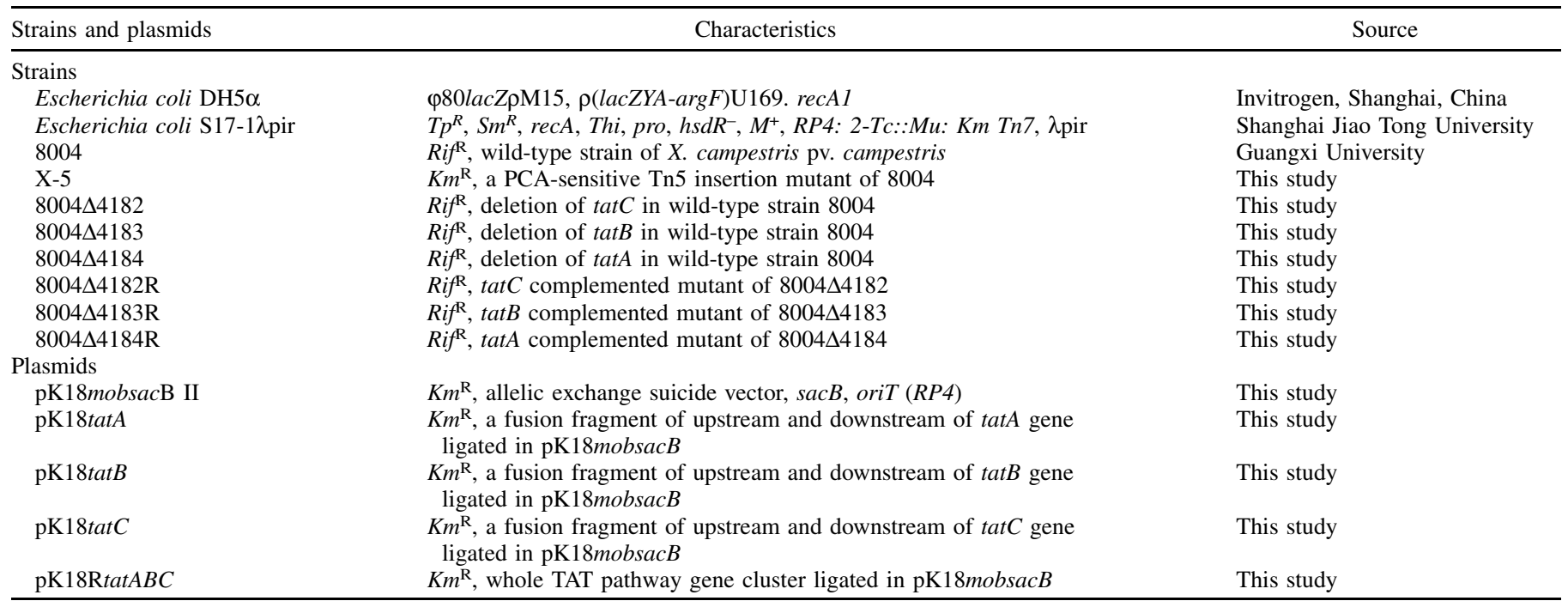


Promoter prediction. Promoter analysis was conducted on the Softberry website (http://www.softberry.com) (Solovyev et al. 2010). Sequence fragments from 300-bp nucleotides upstream of tatA to the end of tatC were entered into the program. The results contained the -10 box and -30 box RNA polymerase recognition sites of the promoter.

Construction of the deletion mutants and quantification of the transcripts of the TAT pathway genes. Deletion vectors were constructed and used to transform $X$. campestris pv. campestris cells by the homologous recombination method, as previously described, with minor modifications (Yu et al. 2015). The homologous recombination deletion vectors are shown in Figure 2B. The primers used for amplifying fragments and the fragment information are both listed in Table 2. The positive colonies on NAS plates were subsequently verified by PCR and qRT-PCR. The PCR products were amplified with primer TatF and TatR and then analyzed on $1 \%$ agarose gels. The complemented mutants were constructed with the same method as the genomic sequence of the wild-type (WT) strain. The complemented mutants were verified by the PCR and qRT-PCR (Fig. 2C and D).

For gene expression analysis, the deletion mutants and WT were cultured to an $\mathrm{OD}_{600}$ of around 1.0 (about $10^{9} \mathrm{CFU} / \mathrm{ml}$ ) in a shaker (175 rpm), and total RNA was extracted with the RNA Prep Pure Cell/Bacteria Kit (Tiangen Co. Ltd., Beijing, China) (Pan et al. 2018). The cDNA was generated with a HiScript II Reverse transcription kit (Vazyme Biotech Co. Ltd.). The cDNA was then diluted to $50 \mathrm{ng} / \mu \mathrm{l}$ and used as the template for qRT-PCR. The qRTPCR reaction was conducted using a ChamQ SYBR qPCR Master Mix kit (Vazyme Biotech Co. Ltd.) with the CFX Connect RealTime System (Bio-Rad). The primers used for qRT-RCR are listed in Table 2. Each mutant or WT was represented by three replicates, and the experiment was performed in triplicate.
Measurement of sensitivities to specific bactericides. The sensitivities of the WT or mutants to kanamycin, captan, phenazine, and 1-OH-phenazine, as indicated by survival rate, were determined via a turbidity indicator (Xu et al. 2015). The cultures were grown to an $\mathrm{OD}_{600}$ of approximately 1.0 (about $10^{9} \mathrm{CFU} / \mathrm{ml}$ ) in a shaker $(175$ $\mathrm{rm}$ ) and were then diluted to $1 \times 10^{7} \mathrm{CFU} / \mathrm{ml}$. A $100-\mu \mathrm{l}$ volume of each diluted culture was added to flasks containing $25 \mathrm{ml}$ of NB media amended with different concentrations of each bactericide. After the cultures were shaken $(175 \mathrm{rpm})$ for $24 \mathrm{~h}$ at $28^{\circ} \mathrm{C}$, the turbidity was measured. Each combination of mutants and bactericides was represented by three replicates, and the experiment was performed in triplicate.

Colony morphology and growth assay. For assessment of colony morphology, the cultures were grown to an $\mathrm{OD}_{600}$ of approximately 1.0 (about $10^{9} \mathrm{CFU} / \mathrm{ml}$ ) in a shaker $(175 \mathrm{rpm}$ ) and then diluted to $1 \times 10^{7} \mathrm{CFU} / \mathrm{ml}$. A 2- $\mu$ l volume of diluted culture was spotted onto NA plates and the colonies were photographed after their diameters increased to $1 \mathrm{~cm}$.

Growth rate was determined in NB media (Pan et al. 2017). After the cultures were grown to an $\mathrm{OD}_{600}$ of approximately 1.0 (about $\left.10^{9} \mathrm{CFU} / \mathrm{ml}\right)$ in a Shaker $(175 \mathrm{rpm}), 100 \mu \mathrm{l}$ of each culture was added to flasks containing $25 \mathrm{ml}$ of NB media. The flasks were shaken $(175 \mathrm{rpm})$ at $28^{\circ} \mathrm{C}$ and the $\mathrm{OD}_{600}$ values of the cultures were measured at $3 \mathrm{~h}$ intervals. Each mutant or WT was represented by three replicate flasks, and the experiment was performed in triplicate.

Virulence test. The virulence of the mutants or WT was tested on Chinese radish (Raphanus sativus L. var. radiculus Pers.), which was grown in a greenhouse at $28^{\circ} \mathrm{C}$ with a 12 -h day/night cycle. Seedlings with four expanded leaves were tested with different cultures. After the cultures were grown to an $\mathrm{OD}_{600}$ of approximately 1.0 (about $10^{9} \mathrm{CFU} / \mathrm{ml}$ ), two leaves per seedling
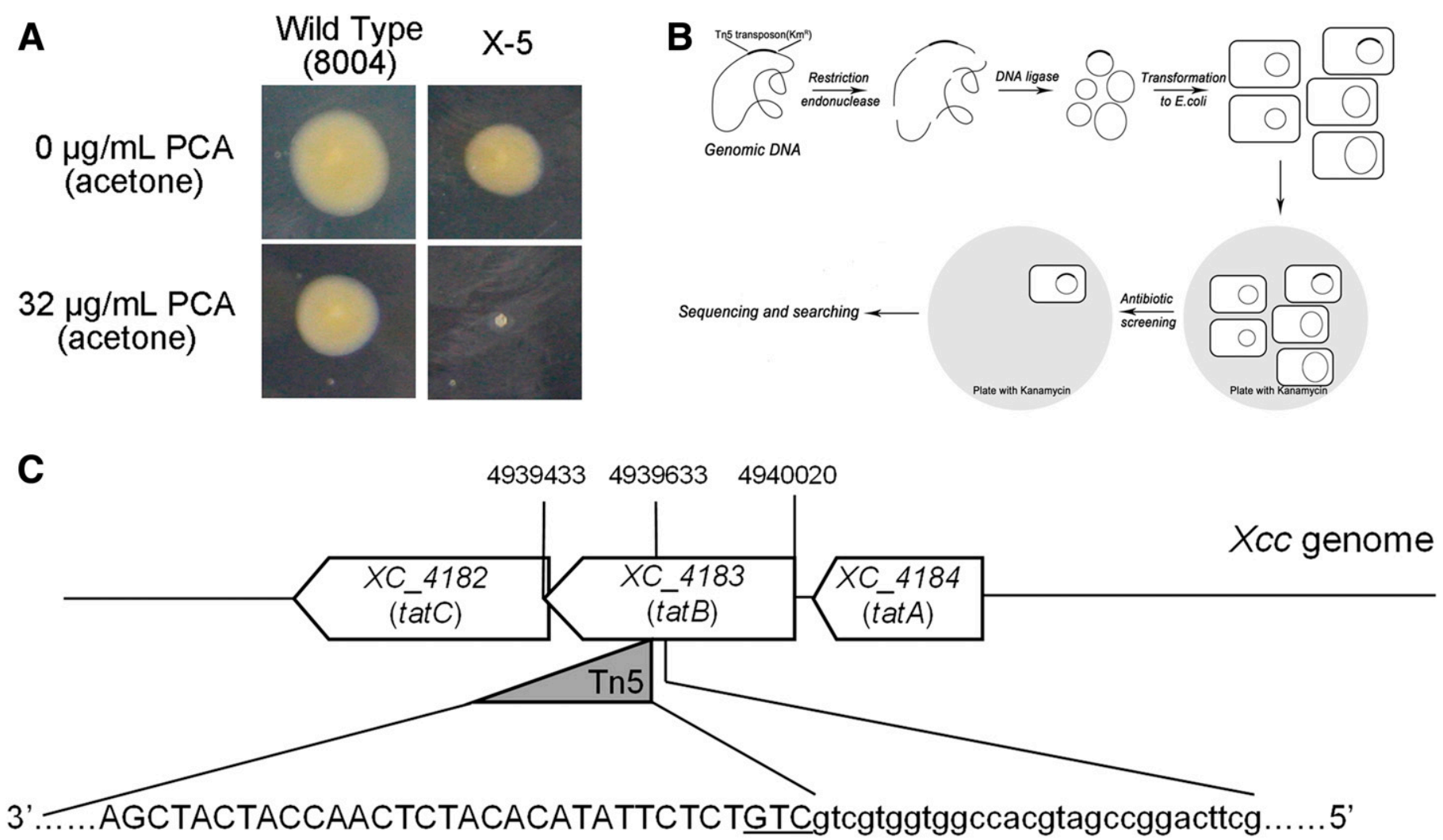

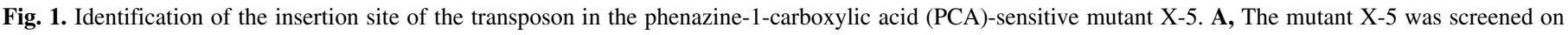

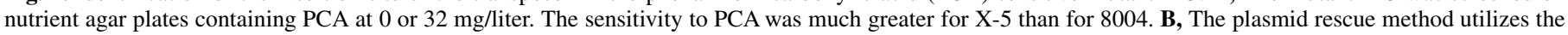

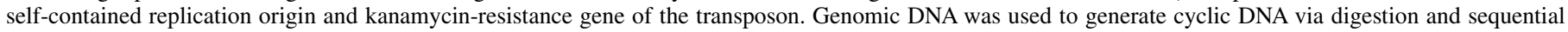

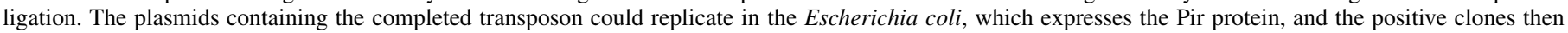

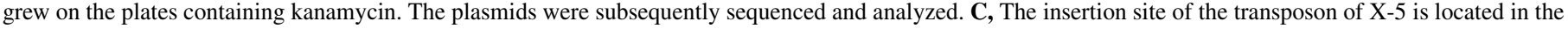
tatB $\left(X C_{-} 4183\right)$ gene. The graph shows the insertion site and transcript orientation of the transposon. 
were inoculated with the leaf-clipping method (Dow et al. 2003). The lesion length was measured after 10 days. Thirty seedlings were inoculated for each mutants, and the experiment was performed in triplicate.

Oxidant accumulation assay. The accumulation of oxidants was assessed with an intracellular oxidants assay kit (Beyotime Co. Ltd., China), which monitored intracellular oxidants with a DCFHDA probe (Pan et al. 2017). The DCFH-DA probe reacts with intracellular oxidants, like ROS and $\mathrm{Fe}^{3+}$, causing fluorescence (Wang and Newman 2008 ). A 1 -ml volume of culture $\left(\mathrm{OD}_{600} \approx 1.0\right.$ ) was centrifuged at $3,500 \times g$ for $5 \mathrm{~min}$, and the pellets were incubated in XCM media containing a DCFH-DA probe for $20 \mathrm{~min}$. The cells were then washed three times with fresh XCM media and added to the wells of a microplate. Each mutant or WT was then treated with PCA at $32 \mathrm{mg} /$ liter in $0.4 \%$ ( $\mathrm{vol} / \mathrm{vol}$ ) acetone or with $0.4 \%$ (vol/vol) acetone alone. The microplate was kept at $28^{\circ} \mathrm{C}$, and the fluorescence was measured with the Spectra Max M5 fluorescence microplate reader (Molecular Devices Co.) for $4 \mathrm{~h}$ with an excitation wavelength of $488 \mathrm{~nm}$ and an emission wavelength of $525 \mathrm{~nm}$. Each treatment was represented by four replicates, and the experiment was performed in triplicate.

$\mathrm{H}_{2} \mathrm{O}_{2}$ tolerance and oxygen consumption rate. For assessment of the $\mathrm{H}_{2} \mathrm{O}_{2}$ tolerance, $2 \mu \mathrm{l}$ of culture $\left(\mathrm{OD}_{600} \approx 1.0\right)$ was spotted onto the NA plates containing $0,0.1,0.2,0.25$, or $0.3 \mathrm{mM}$ of $\mathrm{H}_{2} \mathrm{O}_{2}$ (Pan et al. 2018). When the colony diameter on the non- $\mathrm{H}_{2} \mathrm{O}_{2}$ plate reached $1 \mathrm{~cm}$, all colonies were photographed. Each combination of strains and $\mathrm{H}_{2} \mathrm{O}_{2}$ treatment was represented by nine replicates, and the experiment was performed in triplicate.

The oxygen consumption rate was determined with a Clark electrode, which can monitor the change of oxygen concentration in an intact cell (Barrientos et al. 2009). A 1-ml volume of culture $\left(\mathrm{OD}_{600} \approx 1.0\right)$ was centrifuged at $3,500 \times g$ for $5 \mathrm{~min}$. The pellets were weighed and then resuspended in $1 \mathrm{ml}$ of phosphate-buffered saline buffer ( $50 \mathrm{mM}$ of phosphate, $\mathrm{pH} 7.0)$. The suspensions were added to the cells, which were then monitored for $3 \mathrm{~min}$. The oxygen consumption rate was expressed as $\mathrm{mM}$ of oxygen consumed per gram of pellet per minute. Each mutant or WT was represented by four replicates, and the experiment was performed three times.

\section{RESULTS}

Insertion site and PCA sensitivity of X-5. The mutant X-5 was much more sensitive to PCA than 8004 (Fig. 1A). As determined in NB media, the $\mathrm{EC}_{50}$ values of X-5 and WT under PCA treatment were $0.09 \pm 0.08 \mathrm{mg} / \mathrm{liter}$ and $>32 \mathrm{mg} / \mathrm{liter}$, respectively. An accurate $\mathrm{EC}_{50}$ value could not be calculated when the value was more than $32 \mathrm{mg} /$ liter because of the limited solubility of PCA in broth media. By sequencing the rescued plasmid and employing BLAST against the NCBI database (Fig. 1B), we matched the insertion site with the gene tatB (XC_4183), which encodes a subunit of the TAT complex. Information about the transposon in the genomic DNA is shown in Figure 1C.

Construction of the TAT pathway deletion mutants. The promoter analysis results suggested that the TAT pathway genes share one promoter and are transcribed in the following order: tatA (XC_4184), tatB (XC_4183), and tatC (XC_4182) (Fig. 2A). XC_ $4184, X C_{-} 4183$, and $X C_{-} 4182$ are the respective gene numbers of tat $A, \operatorname{tat} B$, and tat $C$ in a genomic database (Kyoto Encyclopedia of Genes and Genomes, KEGG). To investigate the role of different subunits of the TAT complex in tolerating PCA, we separately deleted the three genes in three mutants. The deletion mutants of tat $A$, tat $B$, and tat $C$ were named $8004 \Delta 4184,8004 \Delta 4183$, and $8004 \Delta 4182$, respectively. The $\mathrm{EC}_{50}$ values of $8004 \Delta 4184$, $8004 \Delta 4183$, and $8004 \Delta 4182$ to PCA were then determined to be $0.112 \pm 0.032,0.098 \pm 0.026$, and $0.13 \pm 0.01 \mathrm{mg} /$ liter, respectively. These values were substantially less than that of the WT ( $>32 \mathrm{mg} /$ liter). $8004 \Delta 4182 \mathrm{R}, 8004 \Delta 4183 \mathrm{R}$, and $8004 \Delta 4184 \mathrm{R}$ were the complementation mutants of $8004 \Delta 4182,8004 \Delta 4183 \mathrm{~m}$, and $8004 \Delta 4184$, respectively. The PCA sensitivities of the complemented mutants $\left(E_{50}\right.$ values to PCA $>32 \mathrm{mg} / \mathrm{liter}$ ) were similar to that of the WT. The deletion mutants were verified by PCR and qRTPCR. The PCR products of the WT, 8004 $44182,8004 \Delta 4183$, and $8004 \Delta 4184$ contained $3,331,2,445,2,887$, and 3,140 bp on the gels, respectively (Fig. 2C). The expression levels of $t a t A$ and $t a t B$ in $8004 \Delta 4182$ (the deletion mutant of tatC) were 1.53-fold and 1.87fold greater, respectively, than in the WT. The expression levels of tat $A$ and tat $C$ in $8004 \Delta 4183$ (the deletion mutant of tatB) were 2.43fold and 2.20-fold greater than in the WT. The expression levels of $t a t B$ and tatC in $8004 \Delta 4184$ (the deletion mutant of tat $A$ ) were

TABLE 2. Primers used in this study

\begin{tabular}{|c|c|c|}
\hline Primers & Sequence & Purpose \\
\hline RP-F & ACСТАСАACAAAGCTCTCATCAACC & Sequence the rescued plasmid \\
\hline RP-R & CTACCCTGTGGAACACCTACATCT & \\
\hline Up tatA F & CGGGATCCCAAGGCCGAAATCTGGTCCTGG & Amplify a 505-bp upstream fragment of tatA gene in $X$. \\
\hline Up tatA R & GGGGTACCCAGTGCCAAATGCTGAAACTGCCCAT & campestris pv. campestris 8004 \\
\hline Down tatA F & GGGGTACCCGCGACCGCGACGCGCGCTG & Amplify a 928-bp downstream fragment of tatA gene in \\
\hline Down tatA $\mathrm{R}$ & GCGTCGACCGCGCTGGTACAGGCCCGGCGC & X. campestris pv. campestris 8004 \\
\hline Up tatB F & GCTCTAGAGCTGTCATCCCCCTG & Amplify a 301-bp upstream fragment of tatC gene in $X$. \\
\hline Up tatB R & GGGGTACCGACGCTGTTCCGG & campestris pv. campestris 8004 \\
\hline Down $\operatorname{tat} B \mathrm{~F}$ & GGGGTACCCCCAGGCACAACC & Amplify a 614-bp downstream fragment of tatC gene in \\
\hline Down tatB $\mathrm{R}$ & CGGGATCCGCCAGCACGAAGT & X. campestris pv. campestris 8004 \\
\hline Up tat $C \mathrm{~F}$ & CGGGATCCGTGTTCGATATTGGGTTT & Amplify a 590-bp upstream fragment of $t a t B$ gene in $X$. \\
\hline Up tatC $\mathrm{R}$ & GGGGTACCCACGGCGTCTTCTCCTGG & campestris pv. campestris 8004 \\
\hline Down tat $C \mathrm{~F}$ & GGGGTACCGATCTGGTTCTAGGGC & Amplify a 642-bp downstream fragment of $t a t B$ gene in \\
\hline Down tatC $\mathrm{R}$ & GCTCTAGACTGCTGATGGTGGCGA & X. campestris pv. campestris 8004 \\
\hline Tat F & CGGGATCCGCGGGTGCTCAACGAGAT & Amplify a 3,331-bp fragment of tat cluster in $X$. \\
\hline Tat $\mathrm{R}$ & GCGTCGACGATGATCGGCCCGAGCGGG & $\begin{array}{l}\text { campestris pv. campestris } 8004 \text { for constructing } \\
\text { complementary mutants }\end{array}$ \\
\hline Probe tat $\mathrm{F}$ & GATCTGGTTCTAGGGC & Amplify a 629-bp probe fragment for Southern blot of \\
\hline Probe tat $\mathrm{R}$ & CTGCTGATGGTGGCGA & deletion mutants \\
\hline Rt-tatC F & TTTCGTGGCGGTGTTCTT & Test the gene expression level of tatC \\
\hline Rt-tatC R & GGGAAGGCCAGCTTCTTT & \\
\hline Rt-tatB F & GATTCGGTCAAGCAGGAACTC & Test the gene expression level of tat $B$ \\
\hline Rt-tatB R & CGACCTGTTGCTGCGTATT & \\
\hline Rt-tatA F & TCGTGCTGCTGGTGTTT & Test the gene expression level of tatA \\
\hline Rt-tatA R & CATGCCCTTCTTGAATTCCTTG & \\
\hline Rt-16S F & GCCTAACACATGCAAGTCGAACGGC & Test the gene expression level of $16 \mathrm{~S}$ sequence \\
\hline Rt-16S R & AATATTCCCCACTGCTGCCTCCCG & \\
\hline
\end{tabular}


2.04-fold and 1.78-fold greater than in the WT (Fig. 2D). These results suggested that the other two genes are expressed more highly in each deletion mutant, indicating that the three TAT pathway genes are all vital for the TAT complex and PCA tolerance in $X$. campestris pv. campestris.
Sensitivities of the TAT pathway deletion mutants to some specific bactericides. Sensitivities of the mutants to the following bactericides were assessed: kanamycin, captan, phenazine, and 1-OH-phenazine. It has previously been shown that antibacterial mechanisms of both kanamycin and captan differ from

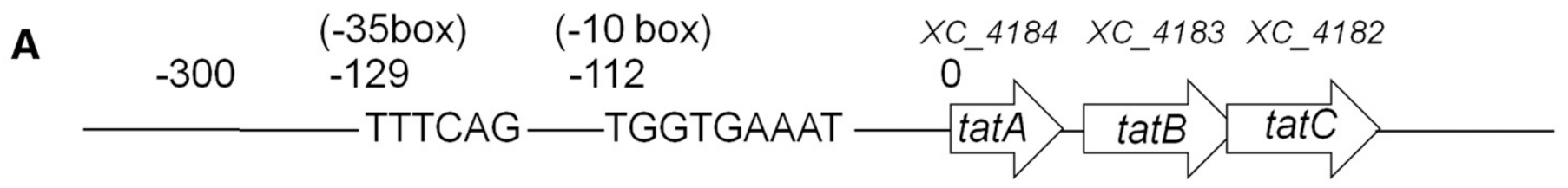

B

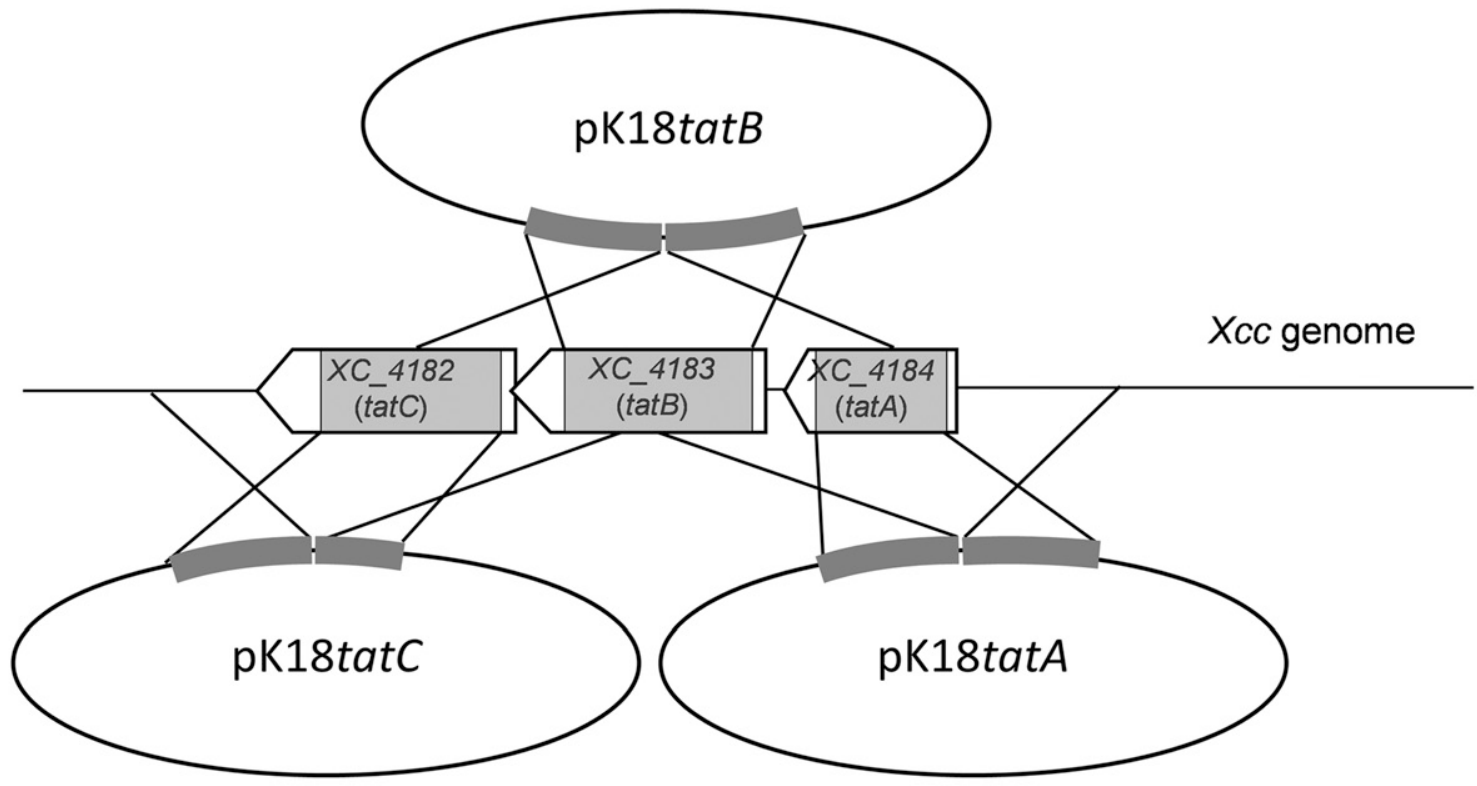

\section{C}

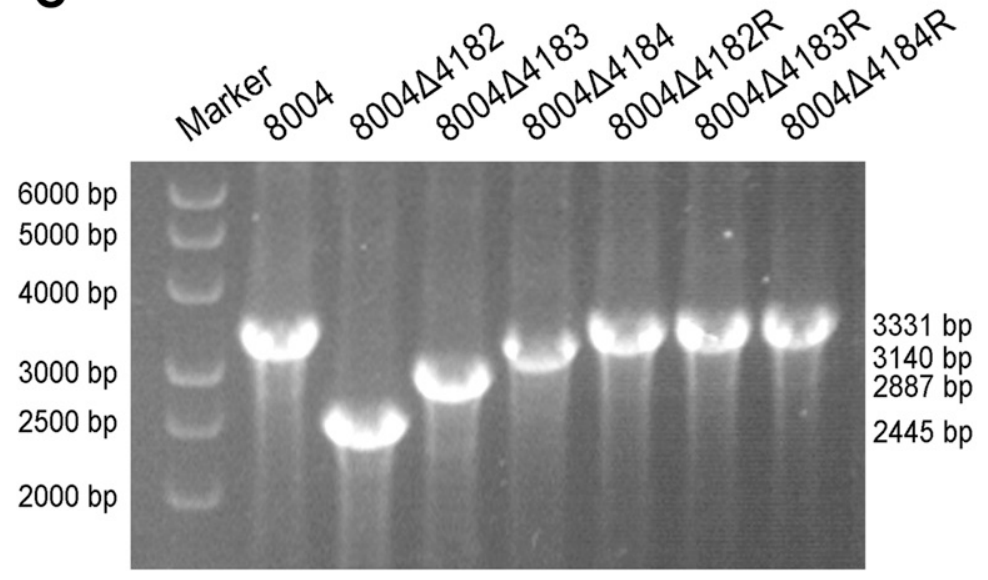

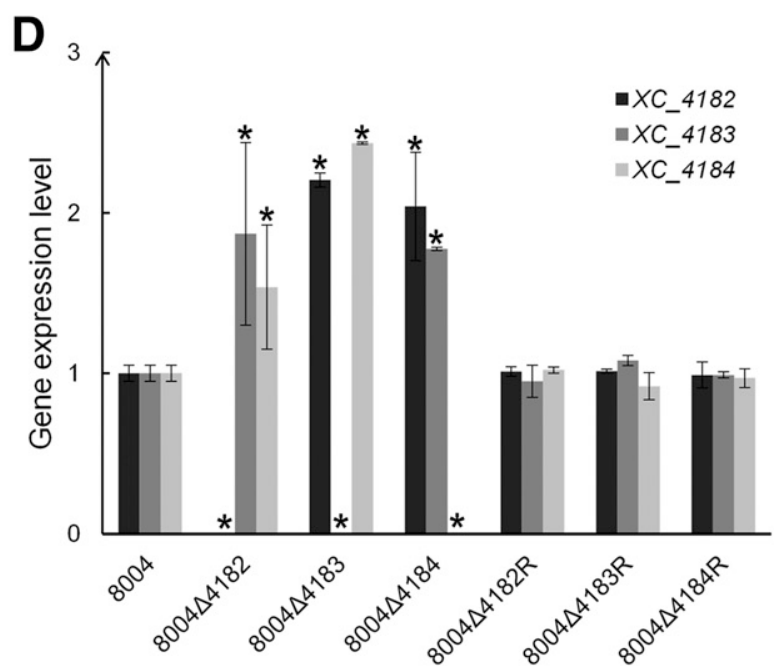

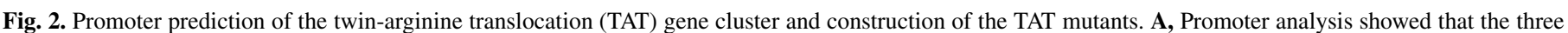

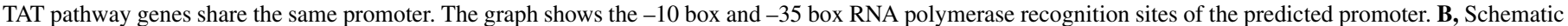

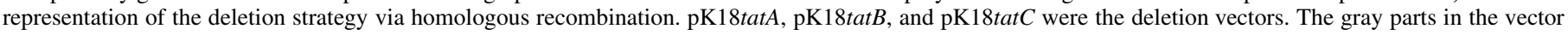

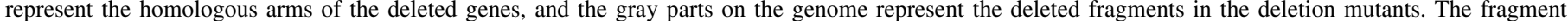

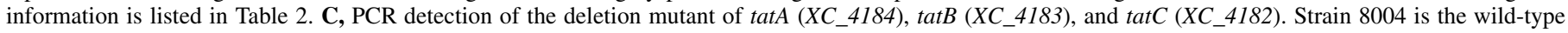

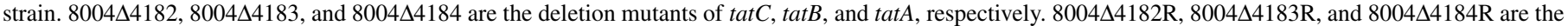

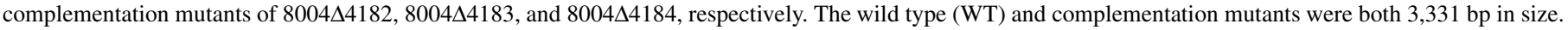

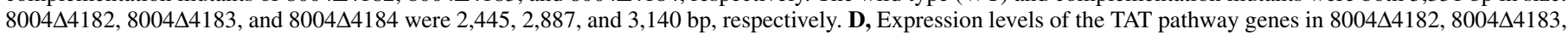

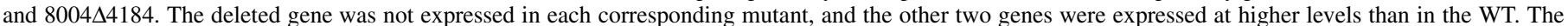

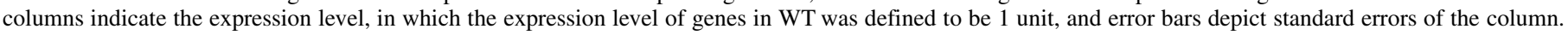

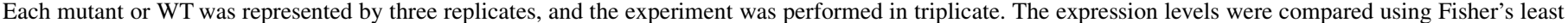
significant difference test. ${ }^{*}, P<0.05$. 
PCA (Alangaden et al. 1998; Barak and Edgington 1984; Jugheli et al. 2009). Phenazine and 1-OH-phenazine are both homologs of PCA (Mavrodi et al. 2010). The sensitivities of the mutants to kanamycin and captan were similar to that of WT (Fig. 3A and B). However, their sensitivities to phenazine and 1-OH-phenazine were significantly increased in comparison with 8004 (Fig. 3C and D).

Biological characteristics. The colony morphologies of the deletion mutants were similar to that of 8004 on the NA plates. The colony shapes were regular, and the surfaces were smooth (Fig. 4A). However, the deletion mutants grew more slowly than 8004 in the NB media (Fig. 4B). The virulence of $8004 \Delta 4182,8004 \Delta 4183$, and $8004 \Delta 4184$ was also substantially decreased compared with the WT (Fig. 4C). The lesion lengths of $8004 \Delta 4182,8004 \Delta 4183$, and $8004 \Delta 4184$ were $1.220 \pm 0.084,1.060 \pm 0.114$, and $1.160 \pm$ $0.089 \mathrm{~cm}$, respectively. The lesion lengths of $8004,8004 \Delta 4182 \mathrm{R}$, $8004 \Delta 4183 \mathrm{R}$, and $8004 \Delta 4184 \mathrm{R}$ were $1.920 \pm 0.130,2.020 \pm 0.277$, $1.880 \pm 0.130$, and $2.080 \pm 0.342 \mathrm{~cm}$, respectively. The decreased growth rate and virulence suggested that the TAT pathway deletion mutants exhibit a fitness defect.

Intracellular oxidant accumulation of the TAT mutants and WT with PCA treatment. In a previous study, the ROS scavenging system played an important role in the PCA tolerance of Xanthomonas species (Pan et al. 2017, 2018). The accumulation of intracellular oxidants in the deletion mutants and 8004 was measured after treatment with control or PCA at $32 \mathrm{mg} / \mathrm{liter}$ for 4 $\mathrm{h}$. Considering that the growth rates differed between the deletion mutants and 8004 , their $\mathrm{OD}_{600}$ values were monitored to evaluate cell density. After the cells were kept in the reader for $4 \mathrm{~h}$, the $\mathrm{OD}_{600}$ values were similar for the deletion mutants and WT, possibly because the microplate is static in the reader, such that multiplication of the cells was restricted. The fluorescence results showed that the intracellular oxidants, indicated as relative fluorescence unit, of the deletion mutants and 8004 all increased with treatment of control, acetone or PCA. Additionally, the deletion mutants and the WT 8004 exhibited a similar accumulation of the intracellular oxidants in response to equal PCA treatment, suggesting that the oxidant scavenging system operated well in the TAT mutants (Fig. 5).

Respiration-related characteristic tests of the TAT mutants and 8004. The characteristics of the TAT mutants observed in the current study were similar to those of the CCM mutants of $X$. campestris pv. campestris, including decreased growth rate and reduced tolerance to phenazines (Wu et al. 2019). These findings motivated us to consider whether the TAT pathway and the CCM system influence the tolerance of $X$. campestris pv. campestris to phenazines through some related metabolic
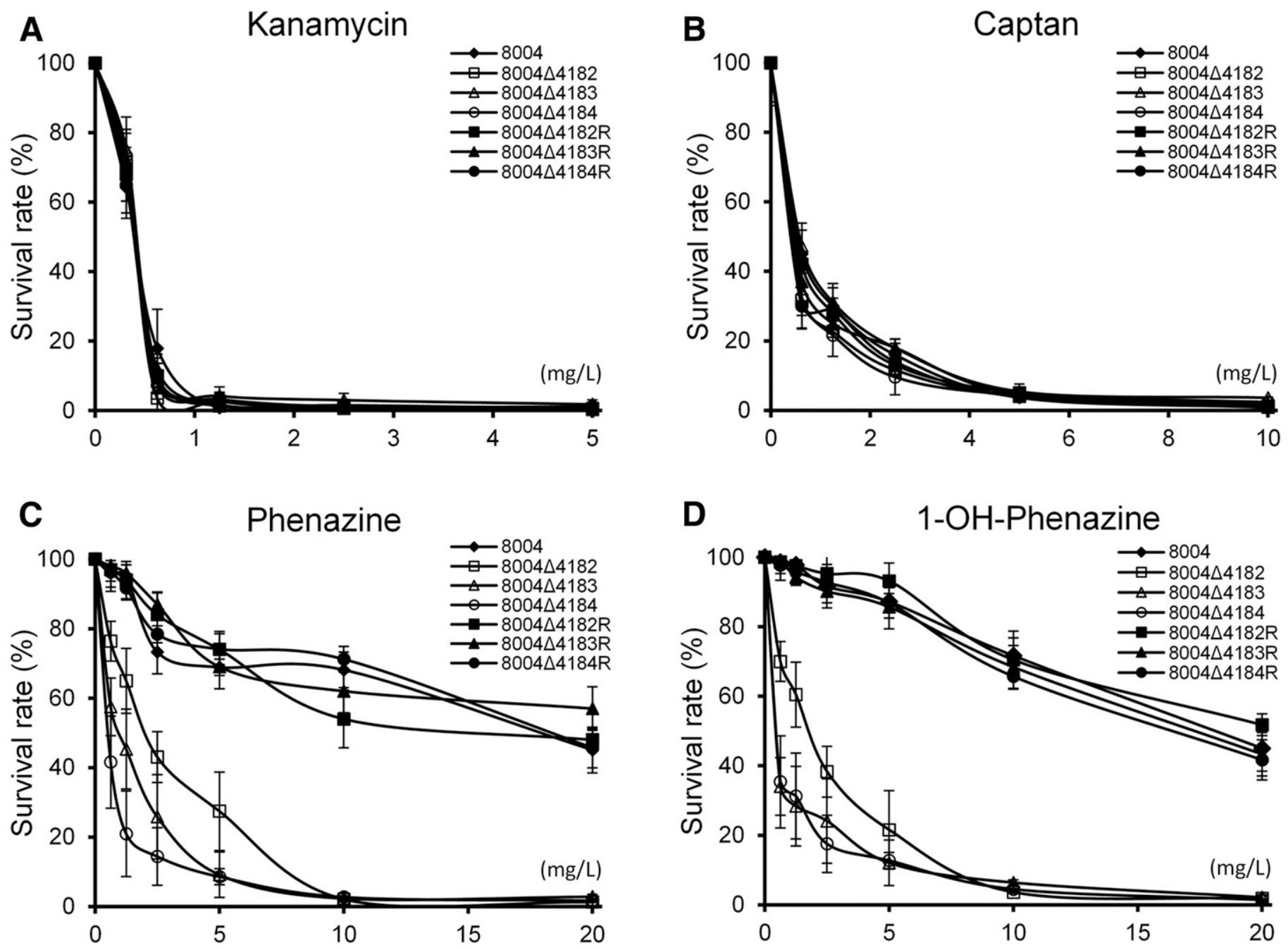

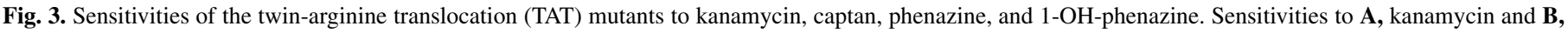

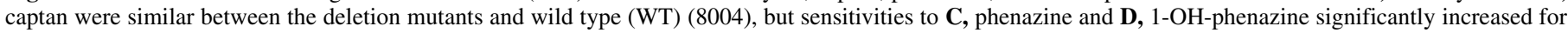

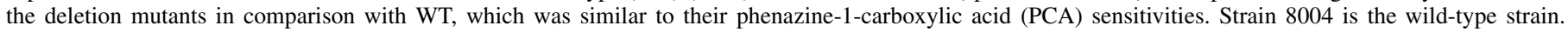

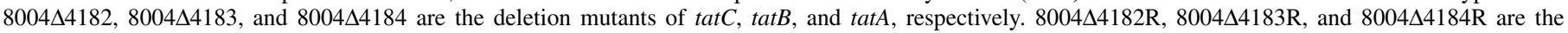

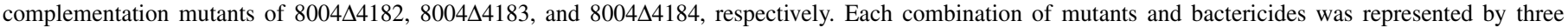
replicates, and the experiment was performed in triplicate. The error bars depict standard errors of the replicates. 
processes. The cytochrome bc1 complex is one obvious possibility because the TAT pathway and CCM complex are involved in its formation. Signal peptide analysis revealed that the iron-sulfur subunit of the cytochrome bc1 complex of $X$. campestris pv. campestris can be recognized by the TAT complex (Fig. 6A) (Fröbel et al. 2012; Qian et al. 2005).

The cytochrome bc1 complex, a key component of the respiratory chain, is responsible for transferring electrons from ubiquinone to some electron receptors. Cytochrome c552 degrades $\mathrm{H}_{2} \mathrm{O}_{2}$ and cytochrome $c$ oxidases consume oxygen, both of which require the electrons supplied by the cytochrome bc 1 complex (Husband et al. 2016; Millett and Durham 2004; Ow et al. 2008). The $\mathrm{H}_{2} \mathrm{O}_{2}$ tolerances and oxygen consumption rates of the deletion mutants were therefore tested to assess whether the cytochrome bc1 complex was functioning in TAT mutants. All three TAT pathway deletion mutants were more sensitive to $\mathrm{H}_{2} \mathrm{O}_{2}$ than the WT 8004 (Fig. 6B). Isolate 8004 and the complementation mutants could tolerate $0.2 \mathrm{mM}$ of $\mathrm{H}_{2} \mathrm{O}_{2}$ on the NA plates, while the deletion mutants could not. The respiratory rates, as indicated by the oxygen consumption rate, were lower for the deletion mutants than for the complemented mutants and 8004 (Fig. 6C). The oxygen consumption rates of $8004,8004 \Delta 4182,8004 \Delta 4183$, and $8004 \Delta 4184$ were $2.692 \pm 0.125 \mathrm{nmol} /(\mathrm{min} \mathrm{mg}), 1.246 \pm 0.181 \mathrm{nmol} /(\mathrm{min}$ $\mathrm{mg}), 1.485 \pm 0.275 \mathrm{nmol} /(\mathrm{min} \mathrm{mg})$, and $1.467 \pm 0.252 \mathrm{nmol} /$ (min $\mathrm{mg}$ ), respectively. The oxygen consumption rates of $8004 \Delta 4182 \mathrm{R}, 8004 \Delta 4183 \mathrm{R}$, and $8004 \Delta 4184 \mathrm{R}$ were $2.543 \pm$ $0.283 \mathrm{nmol} /(\mathrm{min} \mathrm{mg}), 2.797 \pm 0.096 \mathrm{nmol} /(\mathrm{min} \mathrm{mg})$, and $2.677 \pm 0.327 \mathrm{nmol} /(\mathrm{min} \mathrm{mg})$, respectively. The results of $\mathrm{H}_{2} \mathrm{O}_{2}$ tolerance and oxygen consumption rate assays suggested that the cytochrome bc 1 complex is defective in the TAT pathway deletion mutants.

\section{DISCUSSION}

To control bacterial plant diseases, farmers use crop rotation, plant bacteria-free seed, and employ resistant varieties, but these methods have had only limited effect (Roberts et al. 2007; Vicente and Holub 2013; Zhang and Wang 2013). Some bactericides have shown significant effectiveness against bacterial pathogens; however, the use of these bactericides are being restricted because of the antibiotic resistance (Förster et al. 2015; Nuñez et al. 2018; Sundin and Wang 2018). Phenazines, which are extracted from microorganisms, have been studied for a long time for their inhibitory effect on various organisms (Baron and Rowe 1981; Morales et al. 2010; Zhou et al. 2016). In previous studies, Pan et al. (2017, 2018) reported that ROS scavenging ability impacts PCA tolerance in both $X$. oryzae pv. oryzae and X. oryzae pv. oryzicola, and that there are other metabolic processes involved in tolerating PCA more directly in Xanthomonas species. In addition, a Tn5 transposon library of $X$. campestris pv. campestris was constructed to explore which genes are involved in the PCA tolerance of Xanthomonas species (Wu et al. 2019). That study revealed that the CCM system has a more dramatic impact on PCA tolerance than the ROS scavenging system, and the regulation mechanism involved with the CCM system is associated with the function of cytochrome $c$ proteins, which require the CCM system and Dsb (transmembrane thioredox protein) pathway for proper maturation (Pan et al. 2017; $\mathrm{Wu}$ et al. 2019). However, the insertion site of a highly PCAsensitive mutant, X-5 (Fig. 1A), could not be identified with the method of TAIL-PCR, which was used to detect the CCM system insertion mutants. We utilized the plasmid rescue strategy to determine that the insertion site of $\mathrm{X}-5$ is located in the $\operatorname{tat} B(\mathrm{XC}$ 4183) gene, which encodes a subunit of the TAT complex (Fig. 1C).
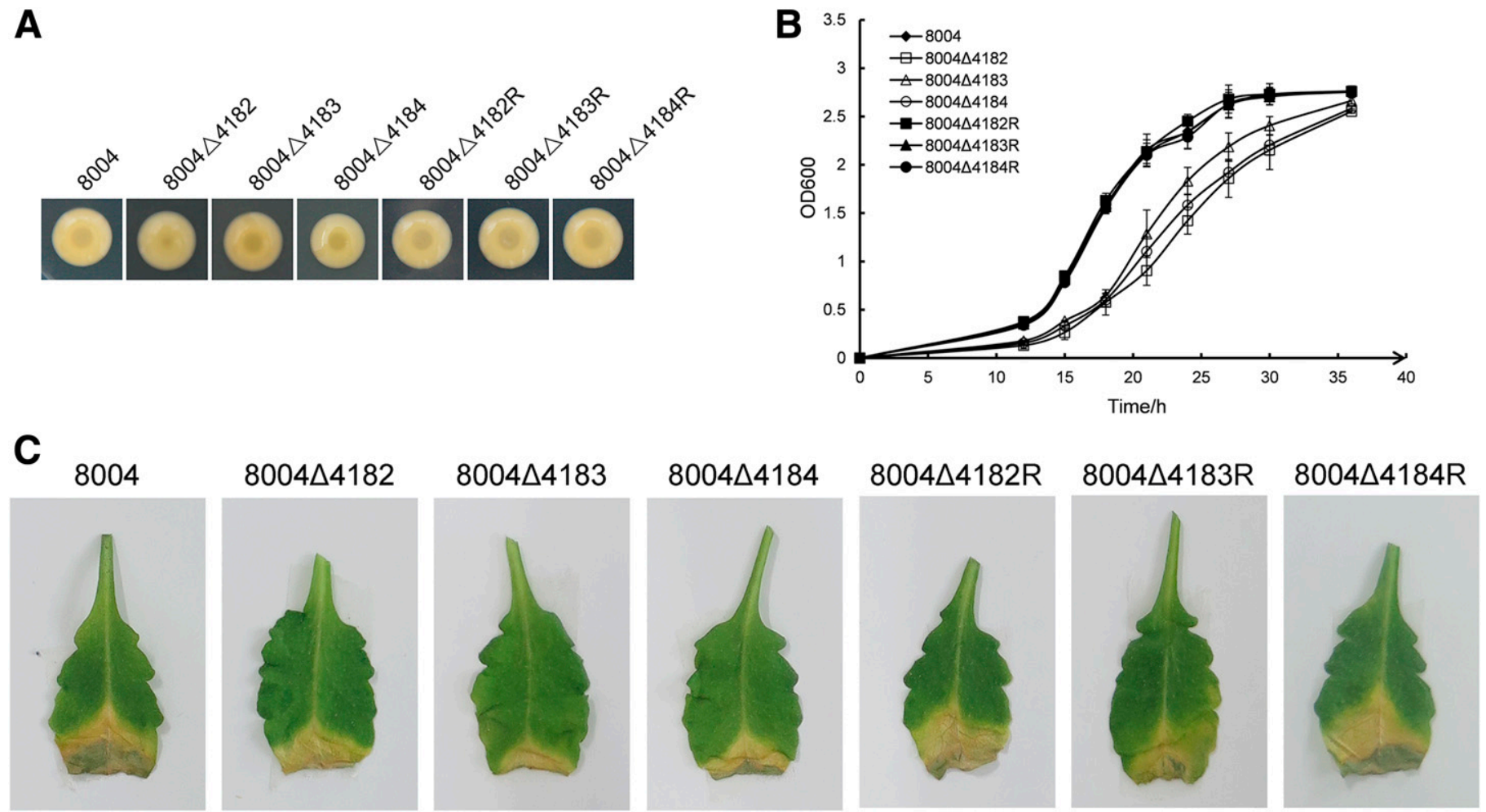

Fig. 4. Colony morphology, growth rate, and virulence of the twin-arginine translocation (TAT) mutants. Strain 8004 is the wild-type strain. $8004 \Delta 4182$, $8004 \Delta 4183$, and $8004 \Delta 4184$ are the deletion mutants of $t a t C$, tatB, and tatA, respectively. $8004 \Delta 4182 \mathrm{R}, 8004 \Delta 4183 \mathrm{R}$, and $8004 \Delta 4184 \mathrm{R}$ are their respective complementation mutants. A, Colony morphology on nutrient agar media. The colonies were photographed after their diameters reached $1 \mathrm{~cm}$. B, Growth rate in the nutrient broth media. The growth rates of the deletion mutants were significantly decreased compared with wild type (WT). Each mutant or WT was represented by three replicate flasks, and the experiment was performed in triplicate. Error bars indicate the standard deviation of three experiments. C, Virulence was tested on Chinese radish with the leaf-clipping method. The virulence of the deletion mutants was substantially decreased compared with that of the WT. Each mutant or WT was inoculated on 60 leaves, and the experiment was performed in triplicate. 
The TAT pathway consists of a hexahelical TatC-type protein and one or two TatA-like proteins (Fröbel et al. 2012). The TAT complex of Xanthomonas species is encoded with conserved nucleotide sequence (Fig. 7) and contains two TatA-like proteins (TatA and TatB) and one TatC protein (Fig. 1C). XC_4184, XC_4183, and $X C_{-}$ 4182 are the respective gene names of tatA, tatB, and tatC in the KEGG genomic database. Promoter analysis showed that $t a t A$, tat $B$, and tat $C$ of $X$. campestris pv. campestris share the same promoter and that the three genes are transcribed in the order of tat $A, \operatorname{tat} B$, and tatC (Fig. 2A), indicating that the inserted transposon might block the expression of tatC in X-5. Considering that TatB is not essential for some species, the decreased PCA tolerance of X-5 might be caused by the defect of TatC. To reveal the role of the three genes in the TAT complex, tat $A, \operatorname{tat} B$, and tat $C$ were separately knocked out in three mutants, which were named $8004 \Delta 4184,8004 \Delta 4183$, and $8004 \Delta 4182$ (Fig. 2C). The expression levels of the three genes in the deletion mutants indicated that the gene cluster of the TAT pathway is driven by one promoter in $X$. campestris pv. campestris and the downstream genes can still be express when an upstream gene is deleted (Fig. 2D). Recently, the different roles of TatA and TatB in E. coli have been reported (Hou et al. 2018), but the exact mechanism of this translocation complex still requires more investigation. However, the results of tolerance to phenazines and other characteristics indicated that the two TatA-like proteins and one TatC protein of $X$. campestris pv. campestris are all essential for the function of the TAT complex in $X$. campestris pv. campestris.

The $\mathrm{EC}_{50}$ values of the TAT pathway deletion mutants to PCA decreased almost 250 folds compared with the WT 8004. In addition to PCA tolerance changes, defects of the TAT complex also impacted tolerance of $X$. campestris pv. campestris to other phenazines but not other types of bactericides. Kanamycin, which is a commonly used antibiotic in labs, interferes with protein

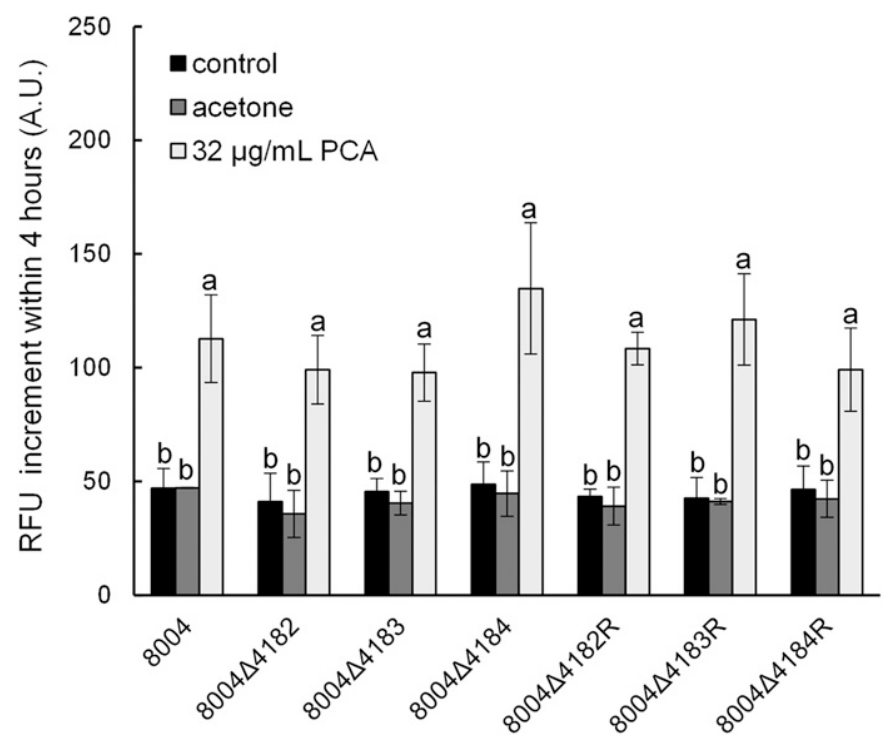

Fig. 5. Oxidant accumulation of the twin-arginine translocation (TAT) mutants after treatment with phenazine-1-carboxylic acid (PCA). The oxidant level is indicated as relative fluorescence unit (RFU); A.U. stands for arbitrary unit. Strain 8004 is the wild-type strain. $8004 \Delta 4182,8004 \Delta 4183$, and $8004 \Delta 4184$ are the deletion mutants of $t a t C$, tat $B$, and $t a t A$, respectively. $\mathrm{R}$ indicates the complementation mutant. The levels of intracellular oxidants of the TAT mutants and wild type (WT) were significantly increased when treated with PCA, while the oxidant accumulation between the TAT pathway deletion mutants and WT was similar with equal PCA treatment. The results of oxidant accumulation indicated that the oxidants induced by PCA can be metabolized in the TAT mutants and are not involved in the decreased tolerance of the TAT mutants to PCA. Each treatment was represented by four replicates, and the experiment was performed in triplicate. Error bars indicate the standard deviation of three replicates, and columns with same letter represent significant differences $(P<0.05)$ according to Fisher's least significant difference test. synthesis, while captan, which is typically used in the field, can interfere with the synthesis of glutathione (Alangaden et al. 1998; Barak and Edgington 1984; Jugheli et al. 2009). Like PCA, phenazine and 1-OH-phenazine are two members of phenazines (Mavrodi et al. 2010). The sensitivities of the three deletion mutants to kanamycin and captan were similar to that of 8004 (Fig. 3A and B). The mutants, however, were more sensitive to phenazine and 1OH-phenazine than the WT 8004 (Fig. 3C and D), indicating that the functions of the TAT complex are specifically involved in the tolerance of $X$. campestris pv. campestris to phenazines. Our previous study also reported that the defective mutants of the CCM system of $X$. campestris pv. campestris were more sensitive to PCA and its phenazine homologs, but not to other types of bactericides (Wu et al. 2019). In addition to the decreased tolerance to phenazines, the deletion mutants of the TAT complex also exhibited reduced fitness-related characteristics. The growth rate and virulence of $8004 \Delta 4184,8004 \Delta 4183$, and $8004 \Delta 4182$ notably decreased compared with 8004 (Fig. 4B and C), suggesting a critical role of the TAT pathway in the growth and infection capability of $X$. campestris pv. campestris. The decreased growth and infection abilities of the TAT mutants might be caused by the essential role of the TAT pathway for many metabolic processes in organisms (Fröbel et al. 2012; Goosens and van Dijl 2017).

Phenazines are well-known for their various negative impacts to organisms, and their ability to cause intracellular ROS accumulation has been studied extensively (Baron and Rowe 1981). In our previous study, we found that PCA treatment can induce the accumulation of intracellular oxidants of Xanthomonas species, and the ROS scavenging system has a weak influence on PCA tolerance in Xanthomonas species (Pan et al. 2018; Xu et al. 2015). However, the tolerance mechanism of the CCM system to phenazines was found to be different from that of the ROS scavenging system. In this study, oxidants were also significantly accumulated in TAT mutants and WT after treatment with PCA (Fig. 5). Furthermore, the accumulated oxidants in response to equal PCA treatment were similar between the TAT mutants and WT, indicating that the oxidants induced by PCA could be metabolized in the TAT mutants and had no impact on the decreased tolerance of the TAT mutants to PCA. Pan et al. (2018) also observed that defects in the ROS scavenging system had limited impact on the PCA tolerance of Xanthomonas species. Mutants of the TAT pathway exhibit dramatic reductions in PCA tolerance compared with the reduction seen in ROS scavenging system mutants, which is similar to that of the CCM system. The $\mathrm{EC}_{50}$ values of the $\operatorname{oxy} R$ or the $C a t B$ deletion mutants to PCA decreased within two to threefold in both $X$. oryzae pv. oryzae and $X$. oryzae pv. oryzicola, while the $\mathrm{EC}_{50}$ values of the deletion mutants of the TAT pathway and CCM system to PCA decreased more than 100-fold. These studies indicated a more critical role of the TAT complex and CCM system in regulating the tolerance of Xanthomonas species to PCA (Pan et al. 2017, 2018; Wu et al. 2019).

The characteristics of the TAT mutants presented in the current study were similar to the CCM mutants. Like the TAT mutants, the CCM mutants exhibited reduced fitness, decreased tolerance to phenazines but unchanged tolerance to other bactericides, and similar accumulation of oxidants to the WT after treatment with equal PCA. Based on the similarities between the mutants of the TAT pathway and CCM system, we suspected that the two metabolic processes impact the tolerance of $X$. campestris $\mathrm{pv}$. campestris to phenazines via related processes. Our previous study revealed that the $\mathrm{CCM}$ system can significantly impact the phenazine tolerance of $X$. campestris pv. campestris by impacting the maturation process of cytochrome $c$ proteins (Wu et al. 2019). Given the functions of the two metabolic processes, we hypothesized that the cytochrome bc1 complex was involved (Fig. 8). The cytochrome bc1 complex is the electron transferring center of the respiratory chain, which is the main energy source of organisms (Ow et al. 2008), and consists of three proteins: cytochrome $b$ 
subunit, iron-sulfur subunit, and cytochrome $\mathrm{C} 1$ subunit (Zara et al. 2009). Maturation of the cytochrome $C 1$ protein requires the CCM system (Stevens et al. 2011; Verissimo and Daldal 2014), and it was reported that defects of the TAT pathway of Streptomyces coelicolor cause an incorrect assembly of the iron-sulfur subunit of the cytochrome bc1 complex (Hopkins et al. 2014). The results of peptide analysis suggested that the signal peptide of the iron-sulfur subunit of $X$. campestris pv. campestris is recognized by the TAT complex (Fig. 6A) (Fröbel et al. 2012; Qian et al. 2005). The TAT system recognizes the substrates via a consensus amino acid sequence. In Proteobacteria, the recognizable sequence is generally defined as "S/T-R-R-x-F-L-K" ( $\mathrm{x}$ is any polar amino acid) where the arginine residues are almost invariant and the other amino acids are found at a frequency exceeding 50\% (Lee et al. 2006). For example, the signal sequences of three most common TAT substrates in E. coli, SufI, TorA, and CueO, are S-R-R-Q-F-I-Q, S-R-R-R-F-L-A,

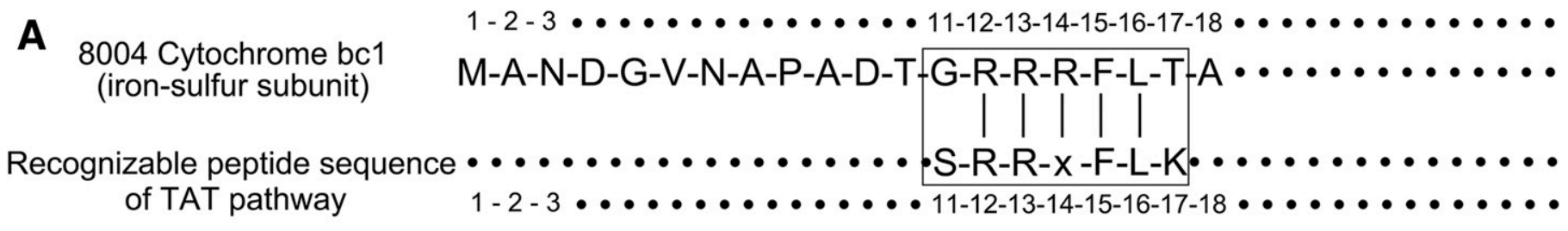

B
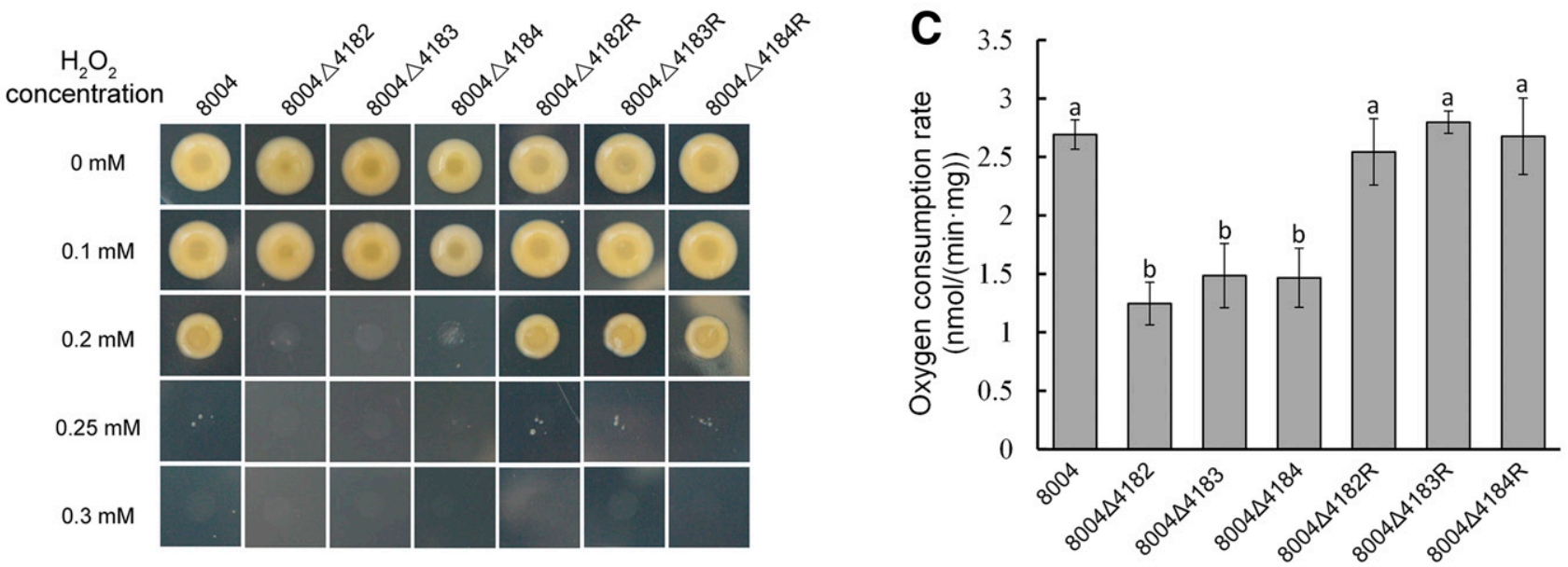

Fig. 6. The signal peptide of the cytochrome bc1 iron-sulfur subunit and the respiration-related characteristic assays of the twin-arginine translocation (TAT) mutants. A, The signal peptide of the cytochrome bc1 iron-sulfur subunit is G-R-R-R-F-L-T in Xanthomonas campestris pv. campestris, which is generally consistent with the TAT pathway recognition signal peptide. The arginine residues are almost invariant, and the other amino acids are found at a frequency exceeding 50\%. The $\mathrm{x}$ in the graph denotes polar amino acids. $\mathbf{B}, \mathrm{H}_{2} \mathrm{O}_{2}$ tolerances of the TAT mutants and wild type (WT) $(8004)$. The $\mathrm{H}_{2} \mathrm{O}_{2}$ tolerances were decreased for the deletion mutants as compared with 8004. Strain 8004 could tolerate $0.2 \mathrm{mM}$ of $\mathrm{H}_{2} \mathrm{O}_{2}$ on the plates, while the deletion mutants could not. Each combination of strains and $\mathrm{H}_{2} \mathrm{O}_{2}$ was represented by nine replicates, and the experiment was performed in triplicate. C, Oxygen consumption rates of the TAT pathway mutants and WT (8004). The oxygen consumption rates were lower for the deletion mutants than for the WT 8004. Each mutant or WT was represented by four replicates, and the experiment was performed in triplicate. Error bars indicate the standard deviation of three replicates, and the columns with same letter are not significantly different $(P<0.05)$ according to Fisher's least significant difference test.

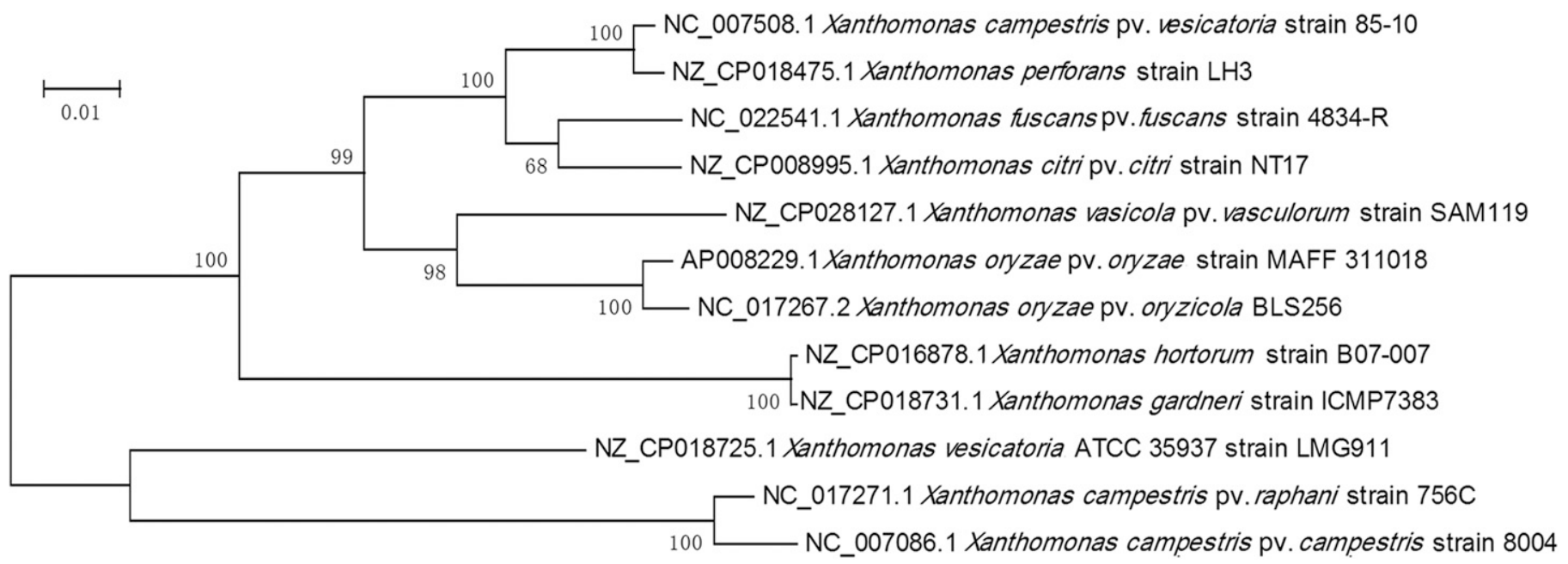

Fig. 7. Homology of the twin-arginine translocation (TAT) pathway of Xanthomonas species. The sequences of the TAT gene cluster of different Xanthomonas species were acquired from the Kyoto Encyclopedia of Genes and Genomes database (KEGG) (http://www.genome.jp/kegg). The cladogram was built using MEGA 5.0 software with 10,000 bootstrap replications performed. The graph suggests the conserved relationship of the TAT pathway genes between Xanthomonas species. 
and Q-R-R-D-F-L-K, respectively (Fröbel et al. 2012). The signal peptide of the cytochrome bc1 iron-sulfur subunit of $X$. campestris pv. campestris is G-R-R-R-F-L-T, which contains conserved arginine residues. Moreover, the results of the $\mathrm{H}_{2} \mathrm{O}_{2}$ sensitivities and oxygen consumption rates indicated that respiration is defective in the TAT mutants (Fig. 6B and C). Cytochrome c552 protein degrades $\mathrm{H}_{2} \mathrm{O}_{2}$ and the cytochrome c oxidases consume oxygen, both of which require electrons supplied by the cytochrome bc1 complex (Berry et al. 2000; Husband et al. 2016). These results suggested that the cytochrome bc 1 may be involved in PCA tolerance, although further study is required to elucidate the mechanism of this interaction.

In this study, we utilized a PCA-sensitive insertion mutant and confirmed that the three subunits of the TAT complex, TatA, TatB, and TatC, are all essential for the functions of the TAT complex in $X$. campestris pv. campestris. The characteristics of the TAT mutants suggested that disruption of the TAT pathway can significantly decrease fitness and phenazines' tolerance in $X$. campestris pv. campestris. Moreover, the similar characteristics (the decreased fitness and tolerance to phenazines) between the TAT and CCM mutants, and the defective respiratory characteristics (decreased oxygen consumption rate and $\mathrm{H}_{2} \mathrm{O}_{2}$ tolerance) of the TAT mutants indicated that the cytochrome bc1 complex is associated with the tolerance mechanism of $X$. campestris pv. campestris to phenazines. Overall, this study sheds new light on the tolerance mechanism to phenazines in Xanthomonas species and suggests new areas of further investigating the mode of action of phenazines and their utility in controlling plant diseases caused by Xanthomonas species.
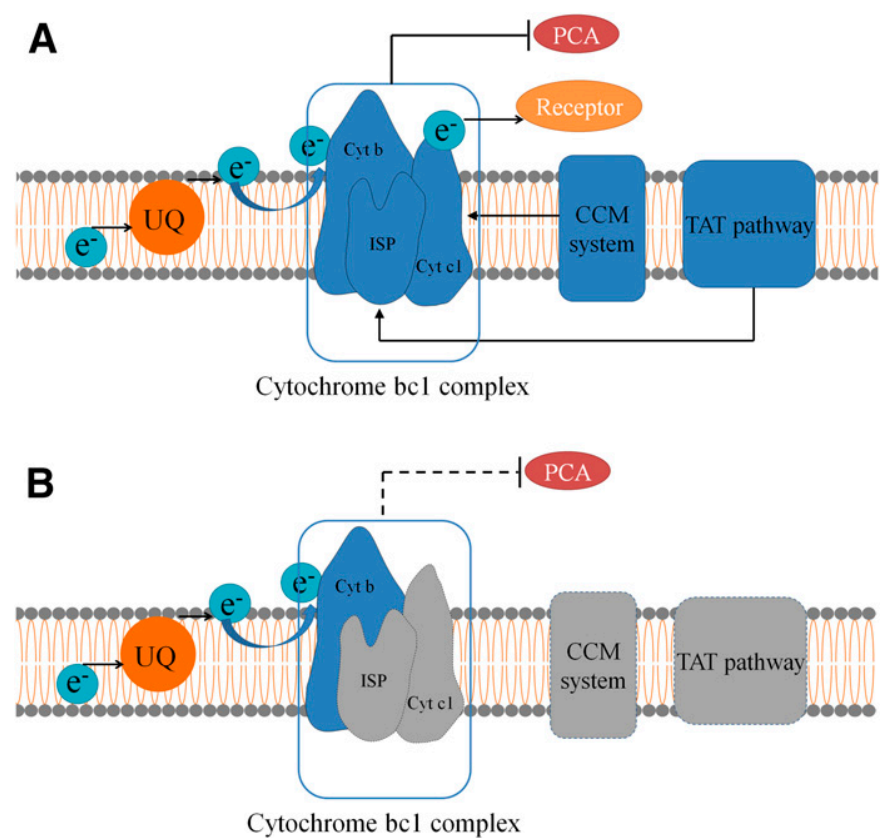

Fig. 8. Diagram of the relationship between twin-arginine translocation (TAT) pathway, cytochrome $c$ maturation (CCM) system, and cytochrome bc1 complex in Xanthomonas campestris pv. campestris. The cytochrome bc1 complex consists of the cytochrome $b$ subunit, the iron-sulfur subunit (ISP), and the cytochrome $\mathrm{C} 1$ subunit. The cytochrome $\mathrm{C} 1$ subunit and the ironsulfur subunit require the CCM system and TAT pathway for proper maturation. The characteristics of the TAT pathway deletion mutants indicated that the cytochrome bc1 complex is associated with the tolerance mechanism to phenazines in $X$. campestris pv. campestris. A, The cytochrome bc 1 complex can function well and increases the tolerance of $X$. campestris pv. campestris to phenazine-1-carboxylic acid (PCA) in wild type (WT). B, The cytochrome bc1 complex cannot be correctly assembled in the deletion mutants of the CCM system and TAT pathway, causing a significant decrease in PCA tolerance.

\section{ACKNOWLEDGMENTS}

We thank TopEdit LLC for the linguistic editing and proofreading during the preparation of this manuscript.

\section{LITERATURE CITED}

Alangaden, G. J., Kreiswirth, B. N., Aouad, A., Khetarpal, M., Igno, F. R., Moghazeh, S. L., Manavathu, E. K., and Lerner, S. A. 1998. Mechanism of resistance to amikacin and kanamycin in Mycobacterium tuberculosis. Antimicrob. Agents Chemother. 42:1295-1297.

Barak, E., and Edgington, L. V. 1984. Glutathione synthesis in response to captan: A possible mechanism for resistance of Botrytis cinerea to the fungicide. Pestic. Biochem. Physiol. 21:412-416.

Baron, S. S., and Rowe, J. J. 1981. Antibiotic action of pyocyanin. Antimicrob. Agents Chemother. 20:814-820.

Barrientos, A., Fontanesi, F., and Díaz, F. 2009. Evaluation of the mitochondrial respiratory chain and oxidative phosphorylation system using polarography and spectrophotometric enzyme assays. Curr. Protoc. Hum. Genet. Unit 19.3.

Berks, B. C. 2015. The twin-arginine protein translocation pathway. Annu. Rev. Biochem. 84:843-864.

Berry, E. A., Guergova-Kuras, M., Huang, L., and Crofts, A. R. 2000. Structure and function of cytochrome bc complexes. Annu. Rev. Biochem. 69:1005-1075.

Cerutti, A., Jauneau, A., Auriac, M. C., Lauber, E., Martinez, Y., Chiarenza, S., Leonhardt, N., Berthomé, R., and Noël, L. D. 2017. Immunity at cauliflower hydathodes controls systemic infection by Xanthomonas campestris pv. campestris. Plant Physiol. 174:700-716.

Costa, T. R., Felisberto-Rodrigues, C., Meir, A., Prevost, M. S., Redzej, A., Trokter, M., and Waksman, G. 2015. Secretion systems in Gram-negative bacteria: Structural and mechanistic insights. Nat. Rev. Microbiol. 13: 343-359.

Dow, J. M., Crossman, L., Findlay, K., He, Y. Q., Feng, J. X., and Tang, J. L. 2003. Biofilm dispersal in Xanthomonas campestris is controlled by cellcell signaling and is required for full virulence to plants. Proc. Natl. Acad. Sci. USA 100:10995-11000.

Du, X., Li, Y., Zhou, Q., and Xu, Y. 2015. Regulation of gene expression in Pseudomonas aeruginosa M18 by phenazine-1-carboxylic acid. Appl. Microbiol. Biotechnol. 99:813-825.

Duan, Y., Ge, C., Liu, S., Chen, C., and Zhou, M. 2013. Effect of phenylpyrrole fungicide fludioxonil on morphological and physiological characteristics of Sclerotinia sclerotiorum. Pestic. Biochem. Physiol. 106: 61-67.

Förster, H., McGhee, G. C., Sundin, G. W., and Adaskaveg, J. E. 2015. Characterization of streptomycin resistance in isolates of Erwinia amylovora in California. Phytopathology 105:1302-1310.

Fröbel, J., Rose, P., and Müller, M. 2012. Twin-arginine-dependent translocation of folded proteins. Philos. Trans. R. Soc. B Biol. Sci. 367: 1029-1046.

Goosens, V. J., and van Dijl, J. M. 2017. Twin-arginine protein translocation. Curr. Top. Microbiol. Immunol. 404:69-94.

Grant, S. G. N., Jessee, J., Bloom, F. R., and Hanahan, D. 1990. Differential plasmid rescue from transgenic mouse DNAs into Escherichia coli methylation-restriction mutants. Proc. Natl. Acad. Sci. USA 87:4645-4649.

Gwee Kyo, P., Lim, J. H., Kim, S. D., and Shim, S. H. 2011. Elucidation of antifungal metabolites produced by Pseudomonas aurantiaca IB5-10 with broad-spectrum antifungal activity. J. Microbiol. Biotechnol. 22:326-330.

Hayward, A. C. 1993. The hosts of Xanthomonas. Pages 1-119 in: Xanthomonas. J. G. Swings and E. L. Civerolo, eds. Springer, Dordrecht.

Hopkins, A., Buchanan, G., and Palmer, T. 2014. Role of the twin arginine protein transport pathway in the assembly of the Streptomyces coelicolor cytochrome bc1 complex. J. Bacteriol. 196:50-59.

Hou, B., Heidrich, E. S., Mehner-Breitfeld, D., and Brüser, T. 2018. The TatA component of the twin-arginine translocation system locally weakens the cytoplasmic membrane of Escherichia coli upon protein substrate binding. J. Biol. Chem. 293:7592-7605.

Husband, J., Aaron, M. S., Bains, R. K., Lewis, A. R., and Warren, J. J. 2016. Catalytic reduction of dioxygen with modified Thermus thermophilus cytochrome c552. J. Inorg. Biochem. 157:8-14.

Jalan, N., Aritua, V., Kumar, D., Yu, F., Jones, J. B., Graham, J. H., Setubal, J. C., and Wang, N. 2011. Comparative genomic analysis of Xanthomonas axonopodis pv. citrumelo $\mathrm{F} 1$, which causes citrus bacterial spot disease, and related strains provides insights into virulence and host specificity. J. Bacteriol. 193:6342-6357.

Jugheli, L., Bzekalava, N., De Rijk, P., Fissette, K., Portaels, F., and Rigouts, L. 2009. High level of cross-resistance between kanamycin, amikacin, and capreomycin among Mycobacterium tuberculosis isolates from Georgia and 
a close relation with mutations in the rrs gene. Antimicrob. Agents Chemother. 53:5064-5068.

Laursen, J. B., and Nielsen, J. 2004. Phenazine natural products: Biosynthesis, synthetic analogues, and biological activity. Chem. Rev. 104:1663-1686.

Lee, P. A., Tullman-Ercek, D., and Georgiou, G. 2006. The bacterial twinarginine translocation pathway. Annu. Rev. Microbiol. 60:373-395.

Lu, W., Pan, L., Zhao, H., Jia, Y., Wang, Y., Yu, X., and Wang, X. 2014. Molecular detection of Xanthomonas oryzae pv. oryzae, Xanthomonas oryzae pv. oryzicola, and Burkholderia glumae in infected rice seeds and leaves. Crop J. 2:398-406.

Mavrodi, D. V., Parejko, J. A., Mavrodi, O. V., Kwak, Y. S., Weller, D. M., Blankenfeldt, W., and Thomashow, L. S. 2013. Recent insights into the diversity, frequency and ecological roles of phenazines in fluorescent Pseudomonas spp. Environ. Microbiol. 15:675-686.

Mavrodi, D. V., Peever, T. L., Mavrodi, O. V., Parejko, J. A., Raaijmakers, J. M., Lemanceau, P., Mazurier, S., Heide, L., Blankenfeldt, W., Weller, D. M., and Thomashow, L. S. 2010. Diversity and evolution of the phenazine biosynthesis pathways. Appl. Environ. Microbiol. 76:866-879.

Millett, F., and Durham, B. 2004. Kinetics of electron transfer within cytochrome bc 1 and between cytochrome bc 1 and cytochrome $c$. Photosynth. Res. 82:1-16.

Morales, D. K., Jacobs, N. J., Rajamani, S., Krishnamurthy, M., Cubillos-Ruiz, J. R., and Hogan, D. A. 2010. Antifungal mechanisms by which a novel Pseudomonas aeruginosa phenazine toxin kills Candida albicans in biofilms. Mol. Microbiol. 78:1379-1392.

Nuñez, A., Rodríguez, G., Monteiro, F. P., Faria, A. F., Silva, J., Monteiro, A., Carvalho, C. V., Gomes, L., Souza, R. M., de Souza, J. T., and Medeiros, F. 2018. Bio-based products control black rot (Xanthomonas campestris pv. campestris) and increase the nutraceutical and antioxidant components in kale. Sci. Rep. 8:101099.

Ow, Y. L. P., Green, D. R., Hao, Z., and Mak, T. W. 2008. Cytochrome $c$ : Functions beyond respiration. Nat. Rev. Mol. Cell Biol. 9:532-542.

Palmer, T., and Berks, B. C. 2012. The twin-arginine translocation (Tat) protein export pathway. Nat. Rev. Microbiol. 10:483-496.

Pan, X., Wu, J., Xu, S., Duan, T., Duan, Y., Wang, J., and Zhou, M. 2018. Contribution of OxyR towards differential sensitivity to antioxidants in Xanthomonas oryzae pathovars oryzae and oryzicola. Mol. Plant-Microbe Interact. 31:1244-1256.

Pan, X., Wu, J., Xu, S., Duan, Y., and Zhou, M. 2017. CatB is critical for total catalase activity and reduces bactericidal effects of phenazine-1-carboxylic acid on Xanthomonas oryzae pv. oryzae and X. oryzae pv. oryzicola. Phytopathology 107:163-172.

Qian, W., Jia, Y., Ren, S., He, Y., Feng, J., Lu, L., Sun, Q., Ying, G., Tang, D., Tang, H., Wu, W., Hao, P., Wang, L., Jiang, B., Zeng, S., Gu, W., Lu, G., Rong, L., Tian, Y., Yao, Z., Fu, G., Chen, B., Fang, R., Qiang, B., Chen, Z.,
Zhao, G., Tang, J., and He, C. 2005. Comparative and functional genomic analyses of the pathogenicity of phytopathogen Xanthomonas campestris pv. campestris. Genome Res. 15:757-767.

Roberts, S. J., Brough, J., and Hunter, P. J. 2007. Modelling the spread of Xanthomonas campestris pv. campestris in module-raised brassica transplants. Plant Pathol. 56:391-401.

Solovyev, V. V., Shahmuradov, I. A., and Salamov, A. A. 2010. Identification of promoter regions and regulatory sites. Methods Mol. Biol. 674:57-83.

Stevens, J. M., Mavridou, D. A. I., Hamer, R., Kritsiligkou, P., Goddard, A. D., and Ferguson, S. J. 2011. Cytochrome $c$ biogenesis system I. FEBS J. 278: 4170-4178.

Sundin, G. W., and Wang, N. 2018. Antibiotic resistance in plant-pathogenic bacteria. Annu. Rev. Phytopathol. 56:161-180.

Taylor, J. D., Conway, J., Roberts, S. J., Astley, D., and Vicente, J. G. 2002. Sources and origin of resistance to Xanthomonas campestris pv. campestris in Brassica genomes. Phytopathology 92:105-111.

Verissimo, A. F., and Daldal, F. 2014. Cytochrome $c$ biogenesis system I: An intricate process catalyzed by a maturase supercomplex? Biochim. Biophys. Acta Bioenergetics 1837:989-998.

Vicente, J. G., and Holub, E. B. 2013. Xanthomonas campestris pv. campestris (cause of black rot of crucifers) in the genomic era is still a worldwide threat to brassica crops. Mol. Plant Pathol. 14:2-18.

Wang, Y., and Newman, D. K. 2008. Redox reactions of phenazine antibiotics with ferric (Hydr)oxides and molecular oxygen. Environ. Sci. Technol. 42: 2380-2386.

Wu, J., Pan, X., Xu, S., Duan, Y., Luo, J., Zhou, Z., Wang, J., and Zhou, M. 2019. The critical role of cytochrome $c$ maturation (CCM) system in the tolerance of Xanthomonas campestris pv. campestris to phenazines. Pestic. Biochem. Physiol. 156:63-71.

Xu, S., Pan, X., Luo, J., Wu, J., Zhou, Z., Liang, X., He, Y., and Zhou, M. 2015. Effects of phenazine-1-carboxylic acid on the biology of the plantpathogenic bacterium Xanthomonas oryzae pv. oryzae. Pestic. Biochem. Physiol. 117:39-46.

Yu, X., Liang, X., Liu, K., Dong, W., Wang, J., and Zhou, M. 2015. The thiG gene is required for full virulence of Xanthomonas oryzae pv. oryzae by preventing cell aggregation. PLoS One 10:e0134237.

Zara, V., Conte, L., and Trumpower, B. L. 2009. Biogenesis of the yeast cytochrome bc1 complex. Biochim. Biophys. Acta Mol. Cell Res. 1793: 89-96.

Zhang, H., and Wang, S. 2013. Rice versus Xanthomonas oryzae pv. oryzae: A unique pathosystem. Curr. Opin. Plant Biol. 16:188-195.

Zhou, L., Jiang, H., Sun, S., Yang, D., Jin, K., Zhang, W., and He, Y. 2016. Biotechnological potential of a rhizosphere Pseudomonas aeruginosa strain producing phenazine-1-carboxylic acid and phenazine-1-carboxamide. World J. Microbiol. Biotechnol. 32:50. 